\title{
Domestic Water Supply and Health of Households in the Three Residential Densities in Osogbo, Osun State, Nigeria. *Fadare S.O. and *Olawuni P.O.
}

\section{Abstract}

This paper examines the health effects of domestic water supply in the three residential density areas, in Osogbo, Osun State, Nigeria. Having converted Osogbo representative map into digital format, it was divided into 245 equal grids. One of every two grids was selected and $10 \%$ of the households in each selected grid were systematically chosen for questionnaire administration. The study revealed that, smaller percentage (23.8\%) of respondents in the high residential density have access to public tap and private well in their houses. Also, incidence of diarrhea (23.3\%), stomach ache (20.2\%) and typhoid(14.8\%) is higher than the other two residential densities. The chi square result obtained in each residential density (low $=X 2=27.259 ; p=0.007$; medium $=X 2=15.411 ; p=0.115 ;$ high $=X 2=19.240 ; p=0.008$ ) indicated that there is a significant relationship between water sources and ill health in the three residential densities in osogbo.

Key Words: Water Supply, Domestic, ill health, Environment, Density.

\section{Introduction}

A vailability of fresh-water that is varies widely with geographical location. The quality and quantity of available fresh water is affected by the natural conditions and human activities. Even with the abundance of water on earth, fresh water needed for human use is a fragile and finite resource. Water is vital to maintaining the earth's climate, and it is essential to all forms of life.

Ehindero (2006) opined that 98 percent of the total volume of water on earth 1.41 billion cubic kilometers $\left(\mathrm{Km}^{3}\right)$, is not available for human uses as it occurs as saltwater in oceans, inland seas and deep underground basins, while only 2 percent is available as fresh water. He however noted that only about $2,000 \mathrm{~km}^{3}$ of freshwater, mostly in rivers, is available to satisfy human needs, agriculture and industry.

It is worth noting that the importance attached to the use of water in different homes covers a wide range of many domestic activities. This ranges from drinking to bathing, cooking, toiletries and cleaning of surroundings and drains. Inability to have access to water may hinder the smooth livelihood in homes and sanitation. Sanitation in itself is any system that promotes sanitary or healthy living conditions. It also includes systems to manage waste water, storm water, solid waste and household refuse as well as ensuring that people have safe drinking water and enough water for washing and bathing.
In line with accessibility to water supply and sanitation, Murray and Lopez (1996) noted that $5.3 \%$ of all death worldwide is attributed to poor water supply, sanitation and hygiene. In a study conducted by Jacobi $e t$ al (1998), in Sao Paulo, Brazil, it was reported that, $94.4 \%$ of the respondents were connected with public water system, and $59.8 \%$ reported that the supply was unsatisfactory in certain times of the year. In peripheral of Sao Paulo, (Capela Do Socorro), the author reported that $74.0 \%$ have problems with water supply and that the after effect of this relates to problems of household cleanings, and personal hygiene.

When water supplies and sanitary conditions are inadequate, health problems are imminent according to Bateman et al (1998), in an epidemiological study of five African countries. The author asserted that the association between improved sanitation and health is strong or even stronger than the association between water supplies and health. $\mathrm{He}$ went further that health benefits may not associate with improved water supplies in areas where the overall level of sanitation is low; and that water supply should be as close as possible to the point of use, to maximize the health benefits.

However, poor water quality coupled with unsanitary conditions and practices at the household levels, such as absence of sanitary latrines, unsafe waste disposal, over-crowding and unhygienic food preparation, create a dangerous environment with health risks to many households (Surjadi et al, 1994). In a study on residents in slum area, conducted by

*Department of Urban Regional Planning, Obafemi Awolowo University, Ile ife. Nigeria. 
Osinusi and Oyejide (1989) in Ibadan, it was suggested that shortage of water is a factor responsible for common illness in children, ranging from $0-5$ years of age. Timacus and Hill in 1985 surveyed 745 households in Amman, Jordan. Using source of water as an important independent variable, the authors discovered that child and infant mortality is strongly associated with overall dwelling quality and sanitation facilities.

Esrey et al (1990) noted that water and sanitation improvement reduced diarrhoea morbidity substantially. In another report, Esrey et al (1985); Esrey and Habent (1986); Esrey et al (1990) tend to support the notion that water quality improvements are less critical to curbing diarrhoea than water supply and sanitation. Access to water and their quality were examined in the studies by Pickerin 1985; Monteiro and Benicio, 1987; and Merrick 1983, in the Gambia and Brazil. Each of the studies linked water access and quality to infant mortality. Merrick for instance, discovered that in Brazil, access to pipe-borne water accounted for about 90 percent of observed decline in infant deaths.

As observed by Monteiro and Benicio in Sao Paulo, reduction in infant mortality between 1973 and 1986 was linked with improved water supply and sanitation. On the other hand, Richardson et al (1968), made a distinct clarification between water and sanitation. In their study carried out in Rustenburg, South Africa, the authors noted that ill health (Salmonella and Shigella) is still prevalent after provision of high quality water but no other sanitary improvement. This tends to suggest that water accessibility and sanitation go hand-in-hand when considering the issue of household health. In any case, Azurin and alvero (1974), noted that provision of safe drinking water reduced the incidence of cholera by $73 \%$ in Bacolod City, Philipines. Also, Victora et al (1988b), asserted that Infants from houses using public standpipe or well are 4.8 times more likely to die of diarrhoea than those from houses with inhouse piped water in Pelotas, Porto Alegre, Brazil. Again, Pickering (1985) in his retrospective study of child mortality under 3 years in Bakau, Gambia, found risk of death among households using public taps was twice higher than those that connected public tap to their houses. In essence, this may be due to differences that existed between children living in households within the same neighbourhood, whose risk of death probably depend more on the overall environmental and sanitary conditions of the neihgbourhood than those whose risks of death bordered on the individual households' environmental and sanitary conditions.

Most of the above reviewed authors based their studies on infants' mortality but little emphasis was made on the household members' health. This work then considers the entire residents and focused more on supply of water and health of household in the discrete residential density areas in Osogbo.

\section{Study Area}

The development of Osogbo takes the pattern of other Yoruba traditional settlements in Nigeria. The settlements are characterized by old traditional core which is characterised by families with a long history of residence in the city and high population density. Osogbo being a traditional city in the Southwestern Nigeria, shares the same similarities with Ibadan, the largest and one of the oldest cities in Africa. For example, Fadare (1987) noted that there exist three distinct residential densities (low, medium and high residential densities) in Ibadan. Olawuni (1999) identified similar pattern of three residential densities in Osogbo (high, medium and low residential densities).

The high residential density area in Osogbo is comprised of housing that are laid out in traditional compounds with many small rooms, limited open space, almost no road, or formal recreation space, and homogeneous population. The medium residential density area is mostly well laid out, with a regular street plan, having many plots almost completely occupied by two or three-storey buildings. Although, there is attempt to control land use, numerous retail services and other commercial activities exist within the zone, but industries are largely absent. The population in these areas is less homogeneous, consisting of people of diverse ethnic origins. The low residential density area was initially established to provide low rent accommodation for public sector employees in government institutions. These areas also consist typically of detached single family dwellings, with about $78 \%$ having 4-9 persons in the households. In addition, the general level of education, income and car ownership 
is higher than in the other density areas in the study area.

Osogbo covers an area of about 140 square kilometers with population of 819,800 people (1991 census provisional results). Using United Nation's population growth rate of $3.5 \%$, the population of Osogbo within a 17 years interval has increased to about $1,307,581$. This is an indication that the population of this city has increased tremendously over the years, owing to its role as the State capital since 1991. Interestingly, the headquarters of both Olorunda and Osogbo local government areas are located within the city (fig.1).

The supply of water in Osogbo is usually from three major sources, pipe borne water, bore holes and wells. Pipe borne water is supplied from both old and new Ede/Osogbo water scheme located on Erinle River near Ede. The schemes were of 180 million litres per day (mld) and 9 million litres per day (mld) design capacities and $40.66 \mathrm{mld}$ and 3.06 mld production levels respectively. There are also 18 boreholes, 26 public wells and numerous private wells, which compliment the public water supply in Osogbo. The inherent problems of water provision in Osogbo include poor and inadequate distribution system, and pipe leakages due to old and rusty water mains.

Consequently, there is bound to be some health effects of this poor water supply on the people of Osogbo, and this indeed is the main thrust of this paper.

\section{Osun State in Nigeria}

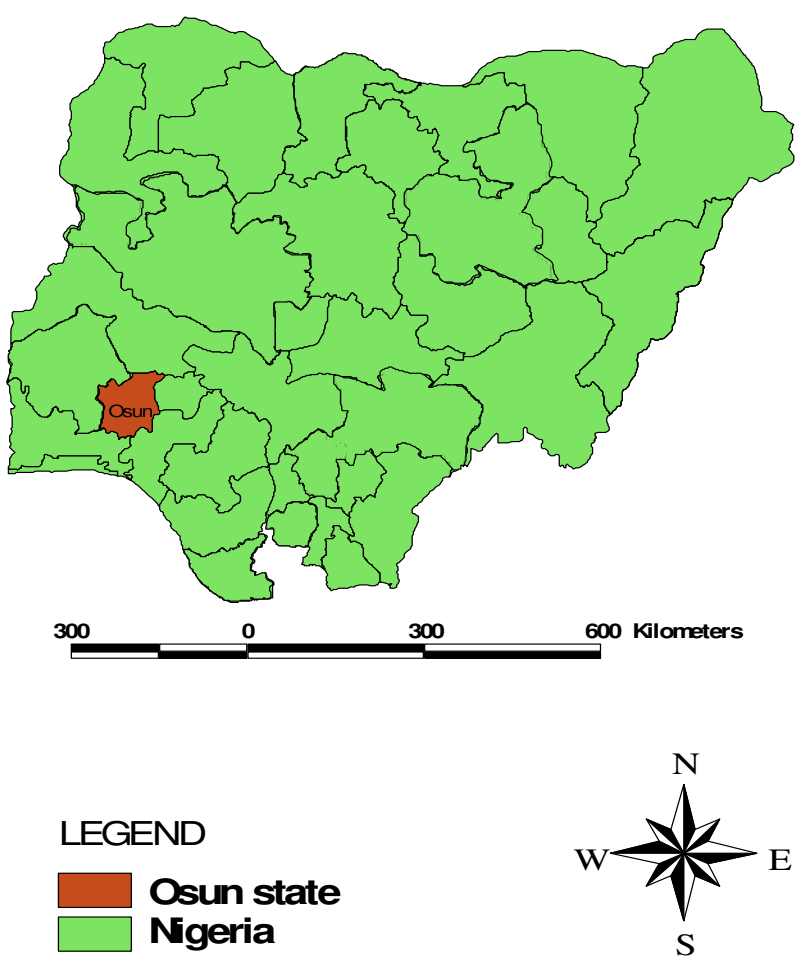

Figure 1 Map of Nigeria Showing Osun State 


\section{Methodology}

The map required for this study was acquired with the use of GIS; the available analogue base map of Osogbo was converted into digital format. The primary data were collected through the use of structured questionnaire that was administered on 432 respondents. The questionnaire covered issues relating to water sources and supply like private public water connection, private well water, public well water, public tap water, rain water and water from steam.

Since households are the targets of the data source for this work and having divided the study area into three residential densities, the map was further subdivided into equal grids of $10 \times 10 \mathrm{~cm}^{2}$ within each socio-economic stratum (low, medium and high income). This is referred to as cell method or fixed grid method based on Samet (1990a). Having divided the study area into equal grids, one of every two grids was selected, and $10 \%$ of the households in each of the selected grids were sampled through a systematic sampling technique in each residential density area (Table 1). From the table, the sample size is 432 houses from the total 4309 , in the three density areas. One household per house is selected for the questionnaire administration. Information collected from the questionnaire formed the basis for the analysis in this paper. The analysis was based on non-parametric tests because the data was nominal and categorical.

\section{Data Analysis and Results \\ Socio-Economic Characteristics of Respondents}

In this section, education levels, occupation and income of respondents in the three residential density areas are discussed. These were done to show the characteristics of respondents in the various residential densities and to justify the eventual analysis of accessibility to water sources and rate of water related diseases in each density area. For instance, accessibility to water supply and rate of water related diseases among households in some cases depends on few socio-economic variables which were discussed in the further analysis, based on density areas.

Socio-economic variables considered relevant to this work are educational levels, occupation and income of respondents as discussed below.
The educational levels of the respondents in the three residential zones are as shown in Table 2 . The table shows that the respondents with Tertiary education are $64.3 \%$ in the low density, $23.7 \%$, Secondary School education, $4.5 \%$, Primary School education and $6.6 \%$ have no formal education. In the medium density, $66.4 \%$ of the respondents have both Tertiary and Secondary School education, $17.9 \%$ have no formal education and $15.7 \%$, Primary school education. Also in the high density, $43.0 \%$ of the respondents have Secondary education, followed by $21.5 \%$ with no formal education. Only $18.3 \%$ have tertiary education and $21.5 \%$ have no formal education. Basically, more than $75 \%$ of the respondents in Osogbo have at least secondary education which suggests a fairly educated society. In any case, it is evident from table 2 that respondents in the high residential density are less literate than their counterparts elsewhere, particularly the low density zone. The $\mathrm{X}^{2}$ value of 65.956 and $\mathrm{p}<0.05$ shows that there is a significant difference between residential densities and educational attainment in the study area.

Table 3 demonstrates the occupation of the respondents in the three residential density zones. It reveals that, in the low density, $34.3 \%$ in private business, $30.3 \%$, (Civil Servants), 25.8\% (Artisan) and 9.6\% are either petty traders or farmers. There is little difference in respondents' occupation in the medium density as $25.0 \%$ are Civil Servants, $24.3 \%$ are Business men or women, $22.1 \%$ each are petty traders and artisans but $6.4 \%$ are farmers. In the high density zone, $31.9 \%$ are petty traders, $29.8 \%$ are Business men or women and $22.3 \%$ are artisan. Only $6.4 \%$ are Civil Servants and $9.6 \%$ are farmers. The table further reveals that in the study area, $30.4 \%$ of respondents are in Private business, followed by artisans and Civil Servants with $23.8 \%$ and $23.4 \%$ respectively. Also, $18.1 \%$ are petty traders and $4.6 \%$ are farmers. The study shows a significant difference between residential densities and occupations of the respondents in the study area. $\left(X^{2}=50.746 ; p=0.001\right)$.

Table 4 shows the income level of respondents in the study area. The table shows that $34.3 \%$ of the respondents earned over 400,000 naira per annum, followed by those who earn 300-400,000 naira per annum. When disaggregated into residential densities, $71.2 \%$ of the respondents in the low density earn over 
N400, 000 per annum, $54.3 \%$ earn N200 N300, 000 per annum in the medium density, and $52.1 \%, \mathrm{~N} 100-\mathrm{N} 200,000$ per annum in the high density. There is no doubt from the foregoing, that there is a variation between residential densities and income level of respondents in the study area.

Before going to discussion on environmental related ill health issues in the three residential density areas, five registered selected hospitals were examined on the cases of environmental related ill health in Osogbo, as shown on table 5 .

The environmental related ill health cases considered with water supply in the present study are diarrhoea, vomiting, stomach ache, typhoid, and malaria. Cholera is ommited here because the itemized ill healths are considered to be symptoms of cholera in some respects. The records of these ill health cases reported in table 5 were collected from five registered hospitals in Osogbo from June 2004 to June 2006. The five registered hospitals are Ladoke Akintola University Teaching Hospital (LAUTECH), State Hospital, Jolayemi Hospital, Strong Tower Maternity Home and Ramat Aderoju Hospital. From the records, and as shown in table 5, malaria cases were $24.8 \%$, followed by typhoid (24.3\%), stomach ache (23.2\%), Diarrhoea $(11.1 \%)$, vomiting $(10.0 \%)$, Cholera $(6.5 \%)$ and cough/common cold $(0.1 \%)$.

The prominent sources of domestic water supply in the study area are, public tap water connections to the houses, private well in the houses, public well and public tap water and hence considered for analysis against possible ill health that may result from the available water supply usage in the density areas. It is important to note the possibility of double responses by the respondents, hence the total responses in this work tends to increase more than the absolute number of the sampled respondents as could be noticed in the results and tables.

Table 6 explains the source of domestic water supply and the incidence of ill health in the low residential density area. Of the respondents in the low residential density that relied on public tap for domestic water use, $13.9 \%$ have malaria, $5.5 \%$ (stomach ache), $4.9 \%$ (diarrhoea) and $4.0 \%$ have typhoid. A total of $26.4 \%$ of all the respondents in this study had public tap water connected to their houses; 2 had private wells are $25.9 \%$ of te total. $17.4 \%$ claimed to have malaria, 5.5\% had stomach ache and 3.0\% (typhoid). There is a generally low case of the incidence of ill health among respondents that depended on public well as shown in table 6 . However, cases of malaria are relatively high among respondents with public tap as water source. Generally, malaria incidence in the low residential density area is $48.3 \%$, followed by stomach ache (17.9\%), typhoid (12.9) and diarrhoea $(12.4 \%)$. The chi square result $\left(\mathrm{X}^{2}=\right.$ $27.259 ; \mathrm{p}<0.05)$ shows that there is relationship between water sources and incidence of ill health in the low residential density area.

Table 7 shows that in the medium residential density area, $39.0 \%$ of the total respondents have access to public tap water for domestic use. The table further shows that $20.9 \%$ of them claimed to usually have malaria, $7.3 \%$ stomach ache and $4.0 \%$ each (typhoid and diarrhea). Also, 24.9\% respondents have private well water in their houses, out of which $12.4 \%$ do regularly have malaria and $3.4 \%$ each vomit and had stomach ache. Of the respondents (23.2\%) who depend on public well in the medium density, $10.2 \%$ usually suffer from frequent malaria and $4.0 \%$ vomiting. Table 7 generally shows that, malaria incidence in this residential area is $47.5 \%$, stomach ache (14 14.1\%), vomiting $(13.6 \%)$ and $12.4 \%$ each (typhoid and diarrhea). The case of malaria is more rampant among respondents who use public tap $(20.9 \%)$, private well $(12.4 \%)$ and public well $(10.2 \%)$ in that order. The chi square result $\left(\mathrm{X}^{2}\right.$ $=15.411 ; \mathrm{p}>0.05)$ shows that is no relationship between water sources and incidence of ill health in the medium residential density area.

Table 8 demonstrates that $47.5 \%$ (which is the highest in the three residential density areas) respondents in the high residential density area depended on public tap water for domestic use, out of which $17.9 \%$ usually have malaria, $11.7 \%$ diarrhoea, 10.3(stomach ache) and 6.3(typhoid). Out of $28.7 \%$ respondents that have access to public well water, $6.7 \%$ usually have diarrhoea, 6.3(malaria), $5.8 \%$ each has typhoid and vomit, and $4.0 \%$ have stomach ache. Of $16.6 \%$ respondents that have private well in their houses for domestic uses, 5.8\% have malaria often, 3.6\% stomach ache, $2.7 \%$ diarrhoea and $2.2 \%$ each has typhoid and vomit. The chi 
square analysis result $\left(X^{2}=19.240 ; p>0.05\right)$ shows that there is a significant relationship between sources of water and incidence of ill health in the high residential density area. This also tends to suggest that water source is capable of determining the incidence of ill health in the area.

In the three residential density areas therefore, dependency on public tap water is very common as well as incidence of malaria. This corroborates the discovery of Pickering (1985) in his retrospective study of child mortality in Bakau, Gambia, that risk of death among households using public tap was twice higher than those that connect public tap to their houses. However, more respondents in the low residential density area have access to private well (25.9\%) and connected public tap (26.4\%) to their houses, than the other two residential densities. The corresponding figures for high density area are $16.6 \%$ private well and $7.2 \%$ tap water connection. In addition, incidence of diarrhoea $(11.7 \%)$ is more pronounced in the high residential density area, especially with respondents that depended on public tap water, than the medium $(4.9 \%)$ and low $4.0 \%$.

Among the three residential density areas, few residents in the high residential density area neither have access to public tap and private well in their houses. Also, incidence of diarrhoea (23.3\%), stomach ache $(20.2 \%)$ and typhoid (14.8\%) is higher in the high residential density area than the other two residential density areas. The chi square results obtained in each density area (low $\mathrm{X}^{2}=$ 27.259; $\mathrm{p}=0.007 ;$ medium $\mathrm{X}^{2}=15.411 ; \mathrm{p}=$ 0.115 ; high $\left.X^{2}=19.240 ; p=0.008\right)$ indicated that there is a significant relationship between water sources and ill health particularly in the low and the high density areas in Osogbo.

\section{Conclusion:}

This work has examined domestic water supply to households in Osogbo and its attending reported health consequences on residents. Water sources considered were

\section{References}

Azurin, J.C., Alvero, M. (1974): "Field Envolution of Environmental sanitation Measures Against Cholera." Bulleting of the World Health Oganisation,51: 19-26. private public water connections, private well water, public well water and public tap water alongside the prominent related ill health incidence. The study revealed that among the three residential densities low residential density area had the highest percentage of public water connections to their private residence. This may be attributed to their status and socio-economic level. On the other hand, the highest dependency on public tap water was in the high residential density area, characterized with low income among other things.

The study further revealed that, malaria incidence is generally rampant in the study area, but it is more severe in the high residential density area particularly among respondents that depended on tap water. Also incidences of diarrhea and stomach ache were higher in the high density area among respondents that depended on public tap water than the other two residential density areas. Also, high residential density area recorded the highest incidence of stomach ache and diarrhea, which may have been due to poor water treatment and lack of adequate in-house storage facilities. On the contrary, residents in the low residential density area who have access to private well recorded the highest malaria incidence. This may have been due to possible existence of mosquitoes in the nearby wells or in the shrubs and trees in their living environment.

In order to maintain good water quality safe for drinking, the portable water in the city must be adequately purified by the public agency responsible for it. In addition, Capacity Building for Community enlightenment on environmental sanitation and hygiene must be articulated, particularly in the high density area, where the effect of poor water supply is mostly felt on the health of the respondents.

Bateman, O.M., Smith, S. and Roark, P. (1993):_A comparism of the Health of Water Supply and Sanitation in Urban and Rural areas of Five African Countries. WASH Field Report No. 398. Water and Sanitation for Health Project, WASH Operations Centre (Arlington, VA). 
Duce,M. and Ojo, A. (1982): Senior Secondary

School Atlas. (Revised Edition) Macmillan pp. 13

Ehindero, O. J. (2006): Environmental Education and Sustainable Development. Literamed

Publications (Nig.) Ltd.

Esrey, S. A. Potash, J. B., Roberts, L. and Schiff, C. (1990): Health Benefits from Improvements in Water Supply and Sanitation: Survey and Analysis of the Literature on Selected Diseases. Technical Report No. 66 Water and Sanitation for Health Project (Arlington, Va).

Esrey, S.A., Feachem, R. G. and Hughes, J.M. (1985): "Interventions for the Control of Diarrhoeal Diseases Among Young Children: Improving Water Supplies and Excreta Disposal Facilities". Bulletin of the World Health Organization. 63 (4): pp757-772.

Esrey, S.A, and Habicht, J. P. (1986): Epidemiologic Evidence for Health Benefits from Improved Water and Sanitation in Developing Countries. Epidemiologic Review. 8: 117-128.

Jacobi, P., Kjellen, M. and Castro, Y. (1998):

Household Environmental Problems in SaoPaulo:Perceptions and Solutions from Centre to Periphery. Urban Environment Series Report

No, 5. Stockholm Environmental Institute

(Stockholm).

Merrick, T.W. (1983): “Access to Piped Water and Early Childhool Mortality in Urban Brazil, 19701976". Working Paper No. 594, World Bank, Washington,D. C.

Mouterio, C. A., Benicio, M. H. A. (1987): "Estudo das condicoes de saude das criancas do municipio de Sao Paulo 1984 - 1985". VI - Doencas respiratorias. Revista de Saude Publica, 21: 380386.
Murray, C.J. L. and Lopez, A. D. (1996): The Global Burden of Disease: A

ComprehensiveAssessment of Mortality and Disability from Diseases, Injuries, and Risk

Factors in 1990 and Projected to 2020. Harvard School of Public Health on Behalf of the World Health Organisation and the World Bank (Cambridge, MA)

Olawuni, P.O. (1999): 'A Study of the Rights of Tenants in Rental Housing in Osogbo, Nigeria'. An Unpublished M.Sc. Thesis, submitted to the Department of Urban and Regional Planniing, Obafemi Awolowo University, Ile-Ife. Nigeria. Osinusi, K., Oyejide, C. (1989)- "Morbidity Pattern Among Nigerian Children from a poor Urban Community". African Journal of Medicine and Medical Sciences 18:43-47.

Pickering, H. (1985): Social and Environmental Factors Associated with Diarrhoea and Growth in Young Children: Child Health in Urban Africa" Social Science and Medicine 21(2): 121-127.

Richardson, N.J., Hayden-Smith, S.,Bokkenhauser, V., Koornhof, H.J. (1968)- "Salmonnellae and Shigellae in Bantu Children Consuming Drinking Water of Improved Quality." South African Medical Journal Vol. 20 p. 46-49.

Samet, H. (1990a): The Design and Analysis of Spatial data Structures. Addison-Wesley. Victora, C.G., Smith, P.G., Vaughan, J.P. et al. (1988b): "Water Supply, Sanitation and Housing in Relation to the Risk of Infant Mortality From Diarrhoea." International Journal of Epidemiology 17(3): 651-654.

Table 1: Sample Size in Densities.

\begin{tabular}{|l|l|l|l|l|}
\hline Densities & $\begin{array}{l}\text { Total No } \\
\text { of Grids }\end{array}$ & $\begin{array}{l}\text { No. of } \\
\text { sampled } \\
\text { Grids }\end{array}$ & $\begin{array}{l}\text { No of building } \\
\text { within sampled } \\
\text { grids }\end{array}$ & $\begin{array}{l}\text { No of sampled } \\
\text { building to make } \\
\text { 10\% coverage. }\end{array}$ \\
\hline High Density & 35 & 19 & 937 & 94 \\
\hline Medium Density & 90 & 46 & 1406 & 141 \\
\hline Low Density & 120 & 60 & 1966 & 197 \\
\hline Total & 245 & 125 & 4309 & 432 \\
\hline
\end{tabular}

Source: Author's Field Work, 2006. 
Table 2: Residential Density and Educational Attainment of Respondents

\begin{tabular}{|c|c|c|c|c|c|c|c|}
\hline \multirow{2}{*}{\multicolumn{2}{|c|}{ Residential Density }} & \multicolumn{5}{|c|}{ Educational Attainment } & \multirow{3}{*}{ Total } \\
\hline & & \multirow{2}{*}{$\begin{array}{l}\text { No formal } \\
\text { Education }\end{array}$} & \multirow{2}{*}{$\begin{array}{l}\text { Primary } \\
\text { Education }\end{array}$} & \multirow{2}{*}{$\begin{array}{l}\text { Secondary } \\
\text { Education }\end{array}$} & \multicolumn{2}{|c|}{ Tertiary Education } & \\
\hline & & & & & $\begin{array}{l}\text { Below } \\
\text { University }\end{array}$ & $\begin{array}{l}\text { University } \\
\text { Education }\end{array}$ & \\
\hline LOW & $\begin{array}{l}\text { Count: } \\
\%\end{array}$ & $\begin{array}{l}13 \\
6.6 \%\end{array}$ & $\begin{array}{l}9 \\
4.5 \%\end{array}$ & $\begin{array}{l}47 \\
23.7 \%\end{array}$ & $\begin{array}{l}69 \\
34 \%\end{array}$ & $\begin{array}{l}60 \\
30.3 \%\end{array}$ & $\begin{array}{l}198 \\
100\end{array}$ \\
\hline MEDIUM & $\begin{array}{l}\text { Count: } \\
\%\end{array}$ & $\begin{array}{l}25 \\
17.9 \%\end{array}$ & $\begin{array}{l}22 \\
15.7 \%\end{array}$ & $\begin{array}{l}30 \\
21.4 \%\end{array}$ & $\begin{array}{l}36 \\
25.7 \%\end{array}$ & $\begin{array}{l}27 \\
19.3 \%\end{array}$ & $\begin{array}{l}140 \\
100\end{array}$ \\
\hline HIGH & $\begin{array}{l}\text { Count: } \\
\%\end{array}$ & $\begin{array}{l}20 \\
21.5 \%\end{array}$ & $\begin{array}{l}16 \\
17.2 \%\end{array}$ & $\begin{array}{l}40 \\
43.0 \%\end{array}$ & $\begin{array}{l}10 \\
10.8 \%\end{array}$ & $\begin{array}{l}8 \\
7.5 \%\end{array}$ & $\begin{array}{l}94 \\
100\end{array}$ \\
\hline TOTAL & $\begin{array}{l}\text { Count: } \\
\%\end{array}$ & $\begin{array}{l}58 \\
13.4 \%\end{array}$ & $\begin{array}{l}47 \\
10.9 \%\end{array}$ & $\begin{array}{l}117 \\
27.1 \%\end{array}$ & $\begin{array}{l}115 \\
26.6 \%\end{array}$ & $\begin{array}{l}95 \\
22.0 \%\end{array}$ & $\begin{array}{l}432 \\
100\end{array}$ \\
\hline
\end{tabular}

Source: Author, 2006. $\quad \mathrm{X}^{2}=65.956 ; \mathrm{p}<0.05$

Table 3: Residential Density and Occupation of Respondents

\begin{tabular}{|l|l|l|l|l|l|l|l|}
\hline \multirow{2}{*}{ Residential Density } & \multicolumn{5}{|c|}{ Occupation } & \multirow{2}{*}{ Total } \\
\cline { 3 - 7 } \multicolumn{2}{|c|}{} & Civil Servant & Business & Farming & $\begin{array}{l}\text { Petty } \\
\text { Trading }\end{array}$ & Artisan & \\
\hline LOW & Count: & 60 & 68 & 2 & 17 & 51 & 198 \\
& $\%$ & $30.3 \%$ & $34.3 \%$ & $1.0 \%$ & $8.6 \%$ & $25.8 \%$ & $100.0 \%$ \\
\hline MEDIUM & Count: & 35 & 34 & 9 & 31 & 31 & 140 \\
& $\%$ & $25.0 \%$ & $24.3 \%$ & $6.4 \%$ & $22.1 \%$ & $22.1 \%$ & $100.0 \%$ \\
\hline HIGH & Count: & 6 & 28 & 9 & 30 & 21 & 94 \\
& $\%$ & $6.4 \%$ & $29.8 \%$ & $9.6 \%$ & $31.9 \%$ & $22.3 \%$ & $100.0 \%$ \\
\hline TOTAL & Count: & 101 & 130 & 20 & 78 & 103 & 432 \\
& $\%$ & $23.4 \%$ & 30.1 & $4.6 \%$ & $18.1 \%$ & $23.8 \%$ & $100.0 \%$ \\
\hline
\end{tabular}

Source: Author 2006. $\quad \mathrm{X}^{2}=50.748 ; \mathrm{p}=0.001$

Table 4: Residential Density and Income Level of Respondents

\begin{tabular}{|l|l|l|l|l|l|l|l|}
\hline \multicolumn{2}{|l|}{ Residential Density } & \multicolumn{2}{|l|}{ Income Level ('000) (Per annum) } & \multirow{2}{*}{ Total } \\
\cline { 3 - 7 } \multicolumn{2}{|l|}{} & $\mathbf{1 0 0}$ & $\mathbf{1 0 0 - 2 0 0}$ & $\mathbf{2 0 0 - 3 0 0}$ & $\mathbf{3 0 0}-\mathbf{4 0 0}$ & $\mathbf{> 4 0 0}$ & \\
\hline LOW & Count: & - & - & - & 57 & 141 & 198 \\
& $\%$ & & & & $28.8 \%$ & $71.2 \%$ & $100.0 \%$ \\
\hline MEDIUM & Count: & - & 14 & 76 & 43 & 7 & 140 \\
& $\%$ & & $10.0 \%$ & $54.3 \%$ & $30.7 \%$ & $5.0 \%$ & $100.0 \%$ \\
\hline HIGH & Count: & 34 & 49 & 10 & 1 & - & 94 \\
& $\%$ & $36.2 \%$ & $52.1 \%$ & $10.6 \%$ & $1.1 \%$ & & $100.0 \%$ \\
\hline TOTAL & Count: & 34 & 63 & 86 & 101 & 148 & 432 \\
& $\%$ & $7.9 \%$ & $14.6 \%$ & $19.9 \%$ & $23.4 \%$ & $34.3 \%$ & $100.0 \%$ \\
\hline
\end{tabular}

Source: Author, 2006.

Table 5: Cases of Environmental Related Ill Health in the Selected Registered Hospitals in the Study Area from June 2004 to June 2005

\begin{tabular}{|l|l|l|}
\hline $\begin{array}{l}\text { Cases of Ill } \\
\text { Health }\end{array}$ & Figure & Percentages \\
\hline Diarrhoea & 37642 & 11.1 \\
\hline Vomiting & 32539 & 10.0 \\
\hline Stomach ache & 78421 & 23.2 \\
\hline Typhoid & 82152 & 24.3 \\
\hline Malaria & 83721 & 24.8 \\
\hline Cholera & 22242 & 6.5 \\
\hline $\begin{array}{l}\text { Cough/Common } \\
\text { Cold }\end{array}$ & 497 & 0.1 \\
\hline TOTAL & $\mathbf{3 3 7 2 1 9}$ & $\mathbf{1 0 0 . 0 0}$ \\
\hline
\end{tabular}

Source: Author's Field Work, 2006. 
Table 6: Domestic Water sources and Ill Health in the Low Residential Density

\begin{tabular}{|l|l|l|l|l|l|l|}
\hline Sources & Diarrhoea & Vomiting. & Stomach ache & Typhoid & Malaria & Total \\
\hline $\begin{array}{l}\text { Public Tap water } \\
\text { Connection }\end{array}$ & $10(4.9)$ & $5(2.4)$ & $8(4.0)$ & $5(2.4)$ & $25(12.4)$ & $55(6.4)$ \\
\hline Private well water & - & - & $11(5.5)$ & $6(3.0)$ & $35(17.4)$ & $52(25.9)$ \\
\hline Public well water & $5(2.4)$ & $6(3.0)$ & $6(3.0)$ & $7(3.5)$ & $9(4.5)$ & $33(6.4)$ \\
\hline Public tap water & $10(4.9)$ & $6(3.0)$ & $11(5.5)_{-}$ & $8(4.0)$ & $28(13.9)$ & $63(31.3)$ \\
\hline Total & $25(12.4)$ & $17(8.5)$ & $36(17.9)$ & $26(12.9)$ & $97(48.3)$ & $201(100.0)$ \\
\hline
\end{tabular}

Source: Author, 2006

$$
\mathrm{X}^{2}=27.259 ; \quad \mathrm{p}=0.007
$$

Table 7: Domestic Water sources and Ill Health in the Medium Residential Density

\begin{tabular}{|l|l|l|l|l|l|l|}
\hline Sources & Diarrhea & Vomiting & Stomach ache & Typhoid & Malaria & Total \\
\hline $\begin{array}{l}\text { Private Tap water } \\
\text { Connection }\end{array}$ & $5(2.8)$ & $6(3.4)$ & $-(0.0)$ & $5(2.8)$ & $7(4.0)$ & $23(13.0)$ \\
\hline Private well water & $5(2.8)$ & $6(3.4)$ & $6(3.4)$ & $5(2.8)$ & $22(12.4)$ & $44(24.9)$ \\
\hline Public well water & $5(2.8)$ & $7(4.0)$ & $6(3.4)$ & $5(2.8)$ & $18(10.2)$ & $41(23.2)$ \\
\hline Public tap water & $7(4.0)$ & $5(2.8)$ & $13(7.3)$ & $7(4.0)$ & $37(20.9)$ & $69(39.0)$ \\
\hline Total & $22(12.4)$ & $24(13.6)$ & $25(14.1)$ & $22(12.4)$ & $84(47.5)$ & \\
& \multicolumn{2}{|l|}{$X^{2}=15.411 ; p=0.115$} & & & $177(100.0)$ \\
\hline
\end{tabular}

Table 8: Domestic Water source and Ill Health in the High Residential Density

\begin{tabular}{|l|l|l|l|l|l|l|}
\hline Sources & Diarrhea & Vomiting & $\begin{array}{l}\text { Stomach } \\
\text { ache }\end{array}$ & Typhoid & Malaria & Total \\
\hline $\begin{array}{l}\text { Private Tap water } \\
\text { Connection }\end{array}$ & $5(2.2)$ & - & $5(2.2)$ & $1(0.4)$ & $5(2.2)$ & $16(7.2)$ \\
\hline Private well water & $6(2.7)$ & $5(2.2)$ & $8(3.6)$ & $5(2.2)$. & $13(5.8)$ & $37(16.6)$ \\
\hline Public well water & $15(6.7)$ & $13(5.8)$ & $9(4.0)$ & $13(5.8)$ & $14(6.3)$ & $64(28.7)$ \\
\hline Public tap water & $26(11.7)$ & $6(2.7)$ & $23(10.3)$ & $14(6.3)$ & $40(17.9)$ & $106(47.5)$ \\
\hline Total & $52(23.3)$ & $24(10.8)$ & $45(20.2)$ & $33(14.8)$ & $72(32.3)$ & $223(100.0)$ \\
\hline
\end{tabular}

Source: Author, $2006 \quad \mathrm{X}^{2}=19.240 \quad \mathrm{p}=0.008$. 